\title{
Diaphragmatic-intercostal breathing and the occurrence of gastroesophageal reflux disease in singers
}

\author{
BJACOBS-DU PLESSIS, ${ }^{1} S$ VILJOEN ${ }^{2}$ AND P BESTER ${ }^{3}$
}

\begin{abstract}
This article was inspired by our awareness of an increasing number of voice students and professional singers who specialize in Western art music and who present with symptoms relating to gastro-esophageal reflux disease (GERD). In our attempts to understand this phenomenon, we began questioning the relationship between diaphragmatic-intercostal breathing (DIB) and the occurrence of GERD. This study uses two of the methods by which qualitative research can be done, namely literature reviews and case studies. The results of the literature review show that the way in which the lower esophageal sphincter (LES) functions during DIB has direct bearing on the possible movement of gastric acids via the esophagus into the pharynx and the larynx. Acknowledging the fact that we are not medical experts, we then used the data from the case studies to suggest how singers might adjust their life styles in order to restrict or prevent occurrences of GERD.
\end{abstract}

Keywords. Diaphragmatic-intercostal breathing; diaphragm; gastroesophagheal reflux disease; lower esophagheal sphincter

\section{Introduction}

This research project was inspired by personal experience of how Gastroesophageal Reflux Disease (GERD) influenced performances of Western art music. As voice pedagogues, we also have been confronted with singing students who present with symptoms related to GERD and we experienced a need for more information on how to guide a student in seeking help for this condition.

This article attempts to understand the relationship between diaphragmatic-intercostal breathing (DIB) 4 and the occurrence of gastro-esophageal reflux disease (GERD) in singers who specialize in Western art music. It is the product of a research project that had its origins

1. Beverley du Plessis is a distinguished soprano who has completed a MMus degree at North-West University, Potchefstroom campus. (beverleyjacobs.j@gmail.com)

2. Dr Santisa Viljoen's from the niche entity Musical arts in Africa: Resources and Applications at NorthWest University, Potchefstroom campus, interdisciplinary research interests are concerned with the relationship between text, context and identity formation, as well as with various aspects of voice pathology. (santisa.viljoen@ nwu.ac.za)

3. Petra Bester obtained a PhD in Nursing. She is actively involved in postgraduate supervision of masters' and doctoral studies positioned within a trans-disciplinary research programme aimed to improve patient and health systems outcomes: Focus area - Quality in Nursing and Midwifery, North-West University, Potchefstroom campus. (petra.bester@nwu.ac.za)

4. While the term ventilation is more commonly used in medicine, this article uses the term breathing as it is more familiar to singers. Furthermore, the abbreviation DIB is used for the sake of stylistic expediency. 
within the contexts of vocal performance and voice pedagogy. An increasing number of voice students present with symptoms relating to GERD and informal conversations with professional singers have also indicated that this is a medical condition with which many have to cope. Because GERD has a definite influence on the singer's voice, it is necessary for the voice pedagogue to not only be aware of the symptoms of GERD, but also to guide the student in seeking help. Therefore, this article has a dual purpose, namely to provide singers and voice pedagogues with sufficient information on the nature of and the relationship between DIB and GERD on the one hand and, on the other hand, to make some suggestions on how a voice pedagogue can assist a student in attempts to manage the occurrence of GERD more efficiently. A brief discussion about each of the main concepts serves as background to this study.

\section{Research design and methods}

The paradigm for the qualitative design used for this article links to postmodern perceptions that boundaries are not absolute and that solving problems is done most effectively by using a holistic approach. A postmodern approach to research takes into account the relationship between the aims, questions and methods of the research project and acknowledges that it be regarded as an entity rather than consisting of separate units (Creswell, 2013:50). It also allows for inter-disciplinary research.

As mentioned previously, this research project followed a qualitative design. According to Durrheim (2006:48) qualitative research is naturalistic, holistic and inductive. This study uses two of the methods by which qualitative research can be done, namely literature reviews and case studies. It employs a systematic use of primary sources such as articles, conference papers, chapters in books and some internet sources to create an integrated literature review of existing research. Ultimately, this data was analysed and a decision was made as to what data meets the criteria recommended by Lincoln and Guba (1985:290) in order to ensure the trustworthiness of the study, namely credibility, applicability, consistency and objectivity.

Due to the origins and focus of this article (voice pedagogy and performance) the research project does not claim to present in-depth case studies reported on by medical doctors. While the discussion about the case studies does include some data based on the feedback from medical doctors that treated the participants, the main focus of the data is on themes relating to how GERD influences the participants' vocal performance and lives.

For the case studies, two participants were chosen to take part in this research project. Both participants are singers, but represent diversity regarding the level of performance, gender, race and social contexts. The first case study is a Caucasian, middle aged male (Barend) ${ }^{5}$ who has a career as a professional opera singer. He is from a middle-class background with access to medical care. The second case study is a young African female (Martie) who is in her final year of undergraduate studies and at the beginning of her career. She comes from a previously disadvantaged community and has very little access to medical care.

Barend provided the researcher with a written document describing his experience of GERD in narrative style. One of the authors of this article (Jacobs-du Plessis) conducted interviews with Martie. The written narrative and the transcriptions of the interviews were used to extract data and, based on the results, prevalent themes were determined.

5. Fictitious names are used. 


\section{Discussion}

\subsection{Diaphragmatic-intercostal breathing process}

The foundation on which the sound of the voice is built is breathing, and like any other foundation it should be properly laid. Ideally, the breathing process for singers will be conducive to producing an ideal sound. ${ }^{6}$ In order to achieve this ideal sound, it is important that the singer's throat is relaxed and open. The open throat feeling is experienced when the larynx is low and free-hanging (Frisell, 2007:106), the mass of the tongue is forward in the mouth and the soft palate is lifted (Ware, 1998:141). Furthermore, it is important that the singer is in proper control of his breathing (Ryan, 2011:50). Managing the constant flow and support of air are important in maintaining this ideal sound throughout a performance. Therefore, it is clear that the term breathing in singing does not subsume only the acts of inhalation and exhalation. It is a process that also involves breath flow and breath support; a process consisting of more than one action and involving various muscles such as the diaphragm, the internal and external muscles and the abdominal muscles. ${ }^{7}$

Davis (1998:10) points out that the most prominent breathing process currently taught for singing is diaphragmatic-intercostal breathing (DIB). It is, in accordance with the statement made in the previous paragraph, a process that includes the management of breath flow and breath support. Various other scholars (Deere, 2005; Miller, 2004; Ryan, 2011) have argued that a combination of diaphragmatic, intercostal and abdominal breathing is more conducive to singing than using each of them alone.

Reasons for this argument include the fact that DIB prevents the larynx from lifting upwards and allows the throat to remain open while the soft palate is lifted. It also ensures optimal resonance. ${ }^{8}$ During inhalation, the contraction of the diaphragm causes the posterior part of the central tendon to move simultaneously down and to the front (Davis, 1998:12). The diaphragm thus 'spreads out' and both the horizontal and vertical dimensions of the pleural cavity and mediastinum in which the heart and lungs are, are expanded. At the same time, the inner walls of the lower ribs are pushed outwards, also contributing to the general expansion of the width of the thorax (Davis, 1998:12; Watson 2009:106) and increases the oxygen intake of the lungs with more than 60 to 80 percentage (Ware, 1998:78-80). These actions cause intra-abdominal pressure because the organs in the abdomen are pushed down and forward. Even the slightest contraction of the diaphragm will cause a bulge in the epigastrium $^{9}$ (Watson, 2009:105).

DIB also manages the air flow on which the sound is carried. During exhalation and phonation, the elastic diaphragm relaxes gradually and returns to its original position. Because singers need to manage the breath flow and breath support during exhalation and

6. An ideal sound is considered a free resonant sound that is placed in the mask of the face (Miller, 1995:37).

7. For detailed discussions on the internal and external intercostal muscles, as well as the internal and external abdominal muscles, see McCoy (2004) and Watson (2009).

8. Resonance is the strengthening of a relatively weak fundamental sound. This amplification of sound is obtained by the resonance of sound in different cavities in the head and the throat. Some of these cavities are classified as true resonators and other as potential resonators. Resonance cavities include the larynx, sinuses, pharynx, oral cavity and cavities in the head (Reid, 1983:140).

9. Epigastrium is the upper, middle portion of the abdomen (Ware, 1998:78-80). 
phonation, the down and outward movement of the diaphragm needs to be balanced with the in- and upward movement of the abdominal muscles. This balance is greatly assisted by the use of the external and internal intercostal muscles that manage both the constant sub-glottal air pressure and the air flow used during exhalation and phonation (Cotrell, 2010:53).

It can thus be concluded that the collaboration between all the muscles involved in DIB contributes to sustaining the ideal sound throughout the performance.

\subsection{Gastroesophageal reflux disease (GERD)}

GERD sufferers are known as individuals who present with any of the physical complications attributed to GERD, or people who have health problems as a result of GERD (Nicholas \& Wiklund, 2005:22). Jahn (2009:5) describes GERD as a condition where gastric acids move upwards into the pharynx ${ }^{10}$ via the esophagus ${ }^{11}$ to the larynx. ${ }^{12}$ These gastric acids, containing hydrochloric acid, pepsin ${ }^{13}$ and bile acids, ${ }^{14}$ are produced in the stomach and move upwards into the esophagus and into the stomach from the duodenum ${ }^{15}$ where they can damage the esophageal walls and vocal folds.

The walls of the stomach, as well as that of the esophagus, are layered with mucosa. Fundic (oxyntic) and pyloric (mucinous) mucosa constitute the two basic types of gastric mucosa in the human body (Treuting et al., 2012:164), while the mucosa in the esophagus consists of three layers, namely the epithelium, the lamina propria and the muscularis mucosae, as well as the submucosa (Treuting et al., 2012:162). Treuting et al. (2012: 162) also point out that the muscularis mucosae are "thicker in the esophagus than in other portions of the digestive tract". It is thus clear that there are differences between the mucosa of the stomach and that of the esophagus.

The combination of the gastric acids in the stomach presents a high $\mathrm{pH}$ gradient with the mucosa uniquely suited to protect the stomach against them. However, when these acids move outside the parameters of the stomach, the sensitive mucosa in the esophagus cannot withstand their high $\mathrm{pH}$ gradient and is thus in danger of erosion and the eventual occurrence of esophageal adenocarsinoma, a cancer of the epithelium in the esophagus. ${ }^{16}$ While bile acids can also contribute towards the erosion of the esophageal mucosa by scarring

10. The pharynx (throat) is about $13 \mathrm{~cm}$ long and extends from the nostrils to the cricoid cartilage. This cartilage is the lowest part of the pharynx (Tortora and Anagnostakos, 1990: 693).

11. Esophagus is the first segment of the gastrointestinal tract, about $23 \mathrm{~cm}$ long, extending from the pharynx to the stomach. (Brink, 2011:224).

12. The larynx, commonly called a voice box, is located between the trachea and the base of the tongue. It consists mainly of cartilages, namely the thyroid and cricoid cartilages, the epiglottis, the paired arytenoids, paired corniculate and paired cuneiformed cartilages (Brink, 2011:437). The only bone in the larynx is the hyoid bone; a very important part of the laryngeal mechanism when it comes to singing as it is directly linked to one of the major articulators, namely the tongue.

13. Pepsin is an enzyme that breaks down protein (Brink, 2011:615).

14. Acids in the stomach that help to digest food (Brink, 2011:930).

15. The duodenum is the upper part of the small intestine attached to the stomach (Brink, 2011:179).

16. Chandrasoma and Demeester (2006) discuss the relationship between GERD and Esophageal Adenocarsinoma in particular detail. 
the fibres at the bottom part of the esophageal epithelium (Brink, 2011:730) - a condition known as Barret's esophageal syndrome, gastric acids are more likely to relate to GERD than bile.

There are various reasons for gastric acids to reflux up into the esophagus. According to Marks (2010:1) GERD can be caused by various physical dysfunctions, including problems with the lower esophageal sphincter (LES) and a hiatus hernia (a specific type of diaphragmatic hernia). While these physical dysfunctions may be the primary causes for GERD, their symptoms are often attributed to a multitude of manifestations, such as intolerance for specific types of food and drinks. This attribution of symptoms to secondary manifestations of GERD, as well as the fact that some patients present with very few or no visual symptoms of this condition, render GERD difficult to diagnose.

Several abnormalities of the LES were found in patients suffering from GERD. Chandrasoma and Demeester (2006:66) explain that the "esophagus ends distally in the lower esophageal sphincter [which is] 3 to 4 centimeters long". Part of the LES is located in the section of the esophagus that can be found in the abdomen - below the diaphragm. The rest, known as the thoracic portion of the LES, is situated above the diaphragm (Chandrasoma \& Demeester, 2006:66). The prevention of GERD depends on the length of the LES as well as its pressure when in a relaxed position. The pressure in the abdominal section of the LES correlates with the intra-abdominal pressure; it increases during inhalation and decreases during exhalation (Chandrasoma \& Demeester, 2006:67). As soon as the length of the abdominal portion of the LES is shortened, for example, due to discrepancies in intra-gastric or intra-abdominal pressures, GERD can occur.

Chandrasoma and Demeester (2006:68) also point out that LES

maintains a sharp pH gradient at the gastro-esophageal junction. Distal to this point, in the stomach, the $p H$ is highly acid (in the 1-3 range). Proximal to this point, in the esophagus, the $\mathrm{pH}$ is in the neutral (approximately 7) range.

Should the LES not prevent the reflux of gastric acids into the esophagus, there is again a danger of esophageal erosion.

Kuipers et al. (2006:36) state that the relation between hiatus hernias and GERD has been acknowledged since the 1950's. They define this type of hernia as "a protrusion of (part of) the stomach and/or other intra-abdominal organs via the esophageal hiatus into the chest" (Kuipers et al., 2006:36). The manner in which a hiatus hernia contributes towards the occurrence of GERD is not absolutely clear. Research conducted by Tougas and Banemai (2001) implies that reflux might be the cause, rather than the result of a hiatus hernia.

The consequences for singers who suffer from GERD are detrimental to their vocal performances. Besides the erosion of the esophageal walls and the thickening of the vocal folds due to chronic inflammation, the upward movement of the larynx, a strong indication of GERD (Jahn, 2009:5), is problematic for a classical singer. While the higher position of the larynx is present in singers who belt $t^{17}$ a particular singing technique often found in light music - this upward movement of the larynx presents a singer of Western art music with a

17. In using the belting technique the larynx is high and the vocal folds are at a very high energy level (Heresniak, 2010:2; Miller, 2004:52). 
major problem. The tension that is created with belting, causes the larynx to close more than what is needed in order to create sound and extra intensity (Heresniak, 2010:1).

Having briefly considered the concepts DIB and GERD, it has become clear that the muscles most relevant to both are the LES and the diaphragm. It has already been explained that, during inhalation, the diaphragm moves down and outwards causing the expansion of the pleural cavity. It was also stated that, in order to balance the working of the diaphragm and abdominal muscles and to manage the breath flow and breath support during exhalation and phonation, the internal and external intercostal muscles keep the diaphragm as low as possible. This process unavoidably contributes to an increase in intra-abdominal pressure. Furthermore, because of this intra-abdominal pressure, the abdominal portion of the LES will be shortened and the possibility of the reflux of gastric acids is exacerbated.

The role that intra-abdominal pressure plays in GERD has also been discussed and it can be argued that this pressure is the biggest commonality between DIB and GERD. Therefore, it is safe to infer that the intra-abdominal pressure that occurs during DIB will not only exacerbate the occurrence of GERD, but that it could also cause it.

It has also been mentioned earlier that DIB is the most effective respiratory process for singers in order to obtain the ideal sound. Therefore, the singer who suffers from GERD can do very little in terms of changing the breathing methods. The best solution would be to consider medical intervention and/or adaptations of lifestyle.

\subsection{The correlation between the singer's lifestyle and the occurrence of GERD}

Earlier in this article, when discussing the research methods used for this project, it was mentioned that two case studies were used as sources for data-gathering. It should be clearly understood that, because the authors of this article are not medical experts, it was never the assumption to present an in-depth medical discussion of the two case studies. but rather to gather and analyse data in order to identify themes specifically related to the correlation between a singer's lifestyle and the occurrence of GERD. The methods used to gather the data, the themes identified through the analyses and the conclusion statements are reflected in the summary of the results on the next page.

\section{Case 1}

In Barend's case, four themes emerged from the written narrative he provided the researchers and each will be discussed with literature integration. The first theme indicated the impact that a professional opera singer's strenuous occupation and lifestyle has on GERD. The professional opera singer's occupation - singing fulltime in opera productions - impacts physically and psychologically on his wellbeing. Rehearsals and performances demand physical exertion while the stress generally experienced by professional singers, impacts them psychologically. In addition, the professional opera singer needs to work hard to keep GERD under control amidst the realities of his career. These realities include singing for long hours per day implying the use of DIB as well as the emotional stress and lifestyle factors such as eating too late, eating just before sleeping and lack of sleep.

With regard to a strenuous lifestyle on GERD, Jones et al. (2007:1452) acknowledge that strenuous physical exercise and work in general have a direct impact on GERD. Authors (Cammarota et al., 2007:890-898) confirm that opera choristers present with a higher occurrence of acid reflux than other members of the population and, therefore, confirmed their hypothesis that gastroesophageal reflux can be occupation-specific (Pregun et al., 
2009:38). In addition, Cammarota et al. (2010:593) confirmed the occurrence of GERD amongst wind musicians. The prevalence of GERD was due to the consistent use of the diaphragm and later impact on the diaphragmatic sphincter functions caused by prolonged straining, inspiration and increased intra-abdominal pressure. With regard to the strenuous physical activity associated in an opera performance, Jozkozv et al. (2006:385) explore the prevalence of GERD in physical activities. They confirm that a constrained body position during exercise causes a disturbance between the two opposite pressures, namely intraabdominal and intrathoracic pressure and that this disturbance influences GERD.

Spiegel et al. (2010:591) point out the effect of nocturnal acid reflux and the impact it might have on the quality of life of those who suffer from it. With regard to the link between psychological stress and GERD, Mizyed and Fass (2009:351) state the prevalence of GERD and psychological co-morbidities in general. These authors (2009:353) acknowledge the link between GERD and the experience of stressful situations, whether the exposure to stress is acute or chronic. The results of research conducted by Naliboff et al. (2004) are of specific interest because they confirmed the correlation between symptoms of heartburn with vital exhaustion (vital exhaustion refers to the measurement of sustained stress symptoms).

The second main theme to emerge indicated that the professional opera singer viewed the active management of GERD as the best solution to the problem. The positive management was evident in two choices made by the participant. The first choice involved making positive lifestyle changes and the second choice was to compliment these changes by accepting medical diagnoses and to participate in pharmacological treatment and surgical interventions. In addition, the professional opera singer made positive lifestyle changes amidst the challenges of his singing career. With regard to the acceptance of GERD, Karademas and Hondronikola (2010:336) concluded that, when people with a chronic cardiac condition accepted the condition, it led to positive subjective health such as emotional wellbeing and physical functioning.

De Groot et al. (2009:1092) acknowledged the positive impact of lifestyle changes as a conservative mechanism on GERD if these lifestyle changes were associated with weight loss. With regard to the role of surgery in GERD, there is contradictory evidence from literature. Cowgill et al. (2007:748) confirm the general satisfaction of the efficiency of laparoscopic Nissen fundiplication surgery and eagerness by patients to undergo this surgery again to keep the signs and symptoms of GERD under control. Watson et al. (2006) also believe in the surgical efficiency in the management of GERD, especially in patients with an absent peristalsis of the oesophagus. However, contrary to these beliefs, Vakil (2007:1365) voices scepticism for surgery as the solution above pharmacological intervention to manage GERD.

The professional opera singer's ability to associate specific signs and symptoms with GERD was the third main theme. The singer is able to manage GERD within the occupational challenges of opera singing because he manages GERD according to specific signs and symptoms. Because the singer uses signs and symptoms as guideline to manage GERD, he takes medication, seeks medical advice and applies specific lifestyle adaptations when experiencing signs and symptoms. 


\section{CASE 1}

Data collection: individual interview, case notes in narrative style, case records (medical reports) (Rule and John, 2011:59), content analysis (Durrheim, 2006:52) conducted.

\section{Main themes from interview:}

1. The professional singer's occupational life is strenuous and impacts on GERD.

2. Active management of GERD is the best solution.

3. GERD characterised by specific signs and symptoms.

4. Signs and symptoms associated with other gastrointestinal, pathophysiological conditions.

Integration of interview results and case records (Rule and John, 2011:64).

\section{Conclusion statements for CASE 1:}

1. A professional male opera singer (Caucasian, $50 \mathrm{yrs}$ ).

2. Middle-class social contexts.

3. Easy access to medical treatment.

4. Has suffered from GERD for more than 30 years.

\section{CASE 2}

Data collection and analysis: individual interview, (Rule and John, 2011:59), content analysis (Durrheim, 2006:52) conducted.

\section{Main themes from interview:}

1. Formal training is critical for the voice student with possible GERD to identify and refer the student.

2. External locus of control over own wellbeing.

3. GERD is a vicious cycle to the voice student.

4. Lifestyle changes are the primary focus to manage GERD.

\section{No case records reported.}

\section{Conclusion statements for CASE 2}

1. An undergraduate, female singer (African, $22 \mathrm{yrs}$ ).

2. Previously disadvantaged community.

3. No medical aid, therefore very little access to medical treatment.

4. Diagnosed with chronic GERD in 2010 after voice pedagogue advised 
Finally the professional opera singer presented with signs associated with other gastrointestinal, patho-physiological conditions indicating that GERD wasn't an isolated condition of the gastrointestinal channel. This singer's complaints of a history of gastro-intestinal disorders such as irritable bowel syndrome, dumping syndrome, gluten intolerance and a history of Barrett's oesophagus were indicative of the extensive scope of signs and symptoms experienced.

While GERD has, in a few cases, been associated with Barret's oesophagus (Ronkainen et al., 2006:1725; Talley \& Wiklund, 2005:21), the relationship between dumping syndrome, gluten intolerance and irritable bowel syndrome and GERD in professional opera singers are unique to this research and has not been confirmed from literature.

\section{Case 2}

As in the first case study, four themes emerged from the data collected during the interviews with the second case study. The first theme relates to how the exposure to formal voice training can lead to referral and management of GERD. The singer first heard about GERD from a trained voice pedagogue when she began formal voice training. The voice pedagogue was instrumental in identifying certain signs and symptoms of GERD, in providing the necessary support and in carefully integrating the management of GERD with voice training.

The importance of the teacher's role in considering the multi-dimensional factors of voice problems in occupational health is confirmed by Smolander and Huttunen (2006:161). They also confirm the role of teachers in promoting voice hygiene, thus preventing further possible damage to the vocal folds. Williams (2011) points out the importance of voice pedagogues in instructing voice students on the correct use of their voices when considering that the voice will be a professional commodity.

Secondly, the voice student presented with an external locus of control of her well-being that impacted directly on the management of her GERD. This student denied the prevalence of GERD, as well as the need to actively manage her condition. The student perceived GERD becoming a real problem once she acknowledged the condition and was convinced that, by denying them, associated signs and symptoms will eventually stop. Because the voice student denied suffering from GERD, she did not understand the potential hazardous impact thereof on her voice, nor did she acknowledge the positive results when managing GERD correctly. Although the voice pedagogue and physician attempted to guide the young singer to manage her GERD, her denial and lack of knowledge prevented her to do so. Finally, the singer experienced that occurrences of GERD were caused and worsened by external factors, such as specific types of food and alcohol.

With regard to the acceptance of an illness, Zalewska et al. (2006:235) conclude that the lack of acceptance of an illness might decrease adherence to medical treatment and cause a delay in clinical improvement. Contrary to their opinion, Telford et al. (2005:457) warn that the simple interpretation of acceptance-denial theory is not advisable, but that the narrative history of a person should be taken into consideration. The inability to accept a chronic condition and present with helplessness cause negative subjective health in patients with chronic cardiac conditions (Karademas \& Hondronikola, 2010:336). In addition Karademas et al. (2012:1248-1249) underscore the clinical significance of a person accepting an illness and the positive relationship between the acceptance of an illness in general and wellbeing and the ability of a person to adjust to an illness. 
The third main theme in the second case study was that GERD was experienced as a vicious cycle that can be described as follows. The singer would present with signs and symptoms of GERD, and would then be referred to a physician by the voice pedagogue. When GERD was diagnosed, the student needed to adhere to pharmacological intervention and absence from singing. The student experienced a remarkable recovering and wanted to sing again. However, when she started to sing again, the voice was strained and the signs and symptoms of GERD would flare up again and the cycle would repeat itself.

Jozkozv et al. (2006:385) confirm that GERD symptoms usually do return and therefore chronic management is supported. Although not referring to a vicious cycle, Feussner (2000:110) proposes an approximate 100\% healing rate in the acute phase of GERD, but less efficiency when treatment is maintained for the rest of a patient's life.

Finally, the singer experienced adaptation of lifestyle as the primary focus in the management of GERD. Through management of food and alcohol intake the student will manage GERD and not through chronic, medical and pharmacological management.

With regard to lifestyle changes, Jozkozv et al. (2006:385) underscore the role of lifestyle and dietary interventions as the basic prevention of GERD, but acknowledge the need for pharmacological management as well. Seidl et al. (2011:145) admits to the effect of alcohol consumption on increased acid reflux. Furthermore Franke et al. (2008:1425) warn that alcohol consumption can worsen GERD. Postma et al. (2002:24) state that a less aggressive reflux treatment approach should manifest. There should be a classification between minor, major and life threatening reflux and this should direct treatment starting from routine lifestyle and dietary modifications when these behaviours might increase reflux risk. The next treatment regime is $\mathrm{H}_{2}$ receptor antagonist or antacid before surgery should be considered.

From the results above it is clear that the singer's career and his lifestyle can contribute to the worsening of GERD. In particular, an obvious connection between the singer's eating program and his routine. Rehearsals and performances overlap with normal mealtimes and singers can, as a result of increased abdominal pressure during singing, also not eat just before he / she sings. It can often happen that a singer eats his main meal late evening when he comes home after a performance or a rehearsal (Sataloff, 1991:10). Furthermore, a singer has certain social obligations such as attending a reception after a performance. There are usually alcohol and food at these events and the food is usually not conducive to healthy dietary habits. These receptions also usually take place late in the evening, causing the singer to eat just before going to sleep. This type of food and beverages worsens GERD and more GERD takes place during the night so it can create more damage to the vocal cords. These unhealthy eating habits lead to weight problems and weight problems exacerbate GERD.

It can be concluded that singers have to make changes in their lifestyle to manage GERD.

\section{Suggestions for voice pedagogues and performers}

The pedagogue can assist a student with advice on how to manage GERD. However, it is of utmost importance that the pedagogue remembers that he is not a medical expert and, therefore, the first step will be to refer the student to a physician. The physician can make recommendations for the treatment of GERD and may prescribe medication that suppresses the production of acid in the stomach. This medication is likely to be accompanied by suggestions for a healthy eating plan. In extreme cases, like a hiatus hernia, the physician may suggest surgery in order to repair the physical problems that cause GERD. 
Voice pedagogues can also assume a role in the physical care of the student who suffers from GERD. Recommendations for the pedagogue can be divided into recommendations for the curriculum content of voice pedagogy and recommendations in the practical teaching of singing.

a) It is recommended that the voice pedagogue include the following concepts in the curriculum of voice pedagogy, thus creating an awareness of GERD.

- The causes and symptoms of GERD

- The relationship between DIA and GERD

- The influence of the singer's lifestyle on GERD

b) It is recommended that voice pedagogues

- refer students suspected of suffering from GERD to the relevant professionals.

- adapt the teaching-learning program of the student's voice studies in order to accommodate and manage the occurrence of GERD.

- suggest that the student rests his voice.

- provide the student with the necessary advise about his condition.

- plays a critical role in the student's acceptance of his condition and encourage him to pro-actively work towards managing his own well-being.

- design a user-friendly brochure that provides information about GERD and make it available to all the students.

Ultimately, the voice pedagogue has to be constantly aware of any signs and symptoms of GERD and how it influences the singer's voice. When these signs manifest, the pedagogue should act with patience and discretion and help the singer to agree not to hurt the voice. The pedagogue also has the difficult task to prepare students for the demanding environment of the professional singer by guiding them in their choices regarding lifestyle.

\section{References}

Brink, A.J. 2011. Woordeboek vir die Gesondheidswetenskappe. Heerengracht: NBUitgewers.

Cammarota, G., Masala G., Cianci, R., Palli, D., Capaccio, P., Schindler, A., Cuoco, L., Galli, J., Ierardi, E., Cannizzaro, O., Caselli, M., Dore, M.P., Bendinelli, B. \& Gasbarrini, G. 2007. Reflux symptoms in professional opera choristers. Gastroenterology, 132(3):890-898. March.

Cammarota, G., Masala, G., Cianci, R., Palli, D., Bendinelli, B., Galli, J., Pandolfi, F., Gasbarrini, A. \& Landolfi, R. 2010. Reflux symptoms in wind instrument players. Alimentary Pharmacology and Therapeutics, 31:593-600. December.

Chandrasoma, P.T. \& Demeester, T.R. 2006. GERD: reflux to esophageal adenocarcinoma. Burlington, MA: Academic Press.

Cotrell, D. 2010. On the voice: Support or resistance? Examining breathing techniques in choral singing. The Choral Journal, 50(9):53-59. April. 
Cowgill, S.M., Gillman, R., Kraemer, E., Al-saadi, S., Villadolid, D. \& Rosemurgy, A. 2007. Ten-year follow up after laparoscopic nissen fundoplication for gastroesophageal reflux disease. The American Surgeon, 73(8):748-753. August.

Creswell, J.W. 2013. Research design: qualitative, quantitative and mixed methods approaches. $4^{\text {th }}$ ed. Thousand Oaks, CAL: Sage.

Davis, R. 1998. A beginning singer's guide. Lanham, MD: Scarecrow Press.

De Groot, N.L., Burgerhart, J.S., Van de Meeberg, P.C., De Vries, D.R., Smout, A.J.P.M. \& Siersema, P.D. 2009. Systematic review: the effects of conservative and surgical treatment for obesity on gastro-oesophageal reflux disease. Alimentary Pharmacology $\mathcal{E}^{\circ}$ Therapeutics,30:1091-1102. September.

Deere, J.D. 2005. Singing in the $20^{\text {th }}$ century: a recollection of performance and pedagogy. Bloomington, IN: Author House.

Durrheim, K. 2006. Research design. (In Terre Blanche, M., Durrheim, K. \& Painter, D., eds. Research in practice: applied methods for the social sciences. 2nd ed. Cape Town, University of Cape Town Press. pp. 33-59).

Feussner, H. 2000. Treatment of gastroesophageal reflux disease: a European view. Digestive Endoscopy, 12:107-111.

Franke, A., Hepp, C., Harder, H., Beglinger, C. \& Singer, M.V. 2008. Esomeprazole reduces gastroesophageal reflux after beer consumption in healthy volunteers. Scandinavian Journal of Gastroenterology. 43:1425-1431. March.

Frisell, A. 2007. The soprano voice: a personal guide to acquiring a superior singing technique. Wellesley: Bradon Books.

Heresniak, $2010 . \quad$ What about belting? http://users.arczip.com/voxnaturalis/studio/belting.html [accessed on 6 November 2011]

Jahn, A.F. 2009. Medical management of the professional singer. Medical Problems of Performing Artists, 24(1):3-9. March.

Jones, R., Coyne, K. \& Wiklund, I. 2007. The Gastro-oesophageal reflux disease impact scale: management tool for primary care. Alimentary Pharmacology E Therapeutics, 25:1451-1459. April.

Jozkozv, P., Wasko-Czopnik, D., Medras, M. \& Paradowski, L. 2009. Gastroesophageal reflux disease and physical activity. Sports medicine, 36(5):385-391.

Karademas, E.C., Tsagaraki, A, \& Lambrou, N. 2012. Illness acceptance, hospitalization stress and subjective health in a sample of chronic patients admitted to hospital. Journal of Health Psychology, 14(8):1243-1250. October.

Kuipers, E.J., Sifrim, D. \& Gooszen, H.G. 2006. Gastroesophageal reflux disease. (In van Lanschot, J.J.B., Gouma, D.J., Tytgat, G.N.J., eds. Integrated medical and surgical gastroenterology. Stuttgart: George Thieme Verlag. pp. 21-41).

Lincoln, Y. \& Guba, E.G. 1985. Naturalistic inquiry. 1st ed. Newbury Park, CA: Sage. 
Marks, J.W. 2010. Gastroesophageal Reflux Disease (GERD, Acid Reflux, Heartburn). http://www.medicinenet.com/gastroesophageal_reflux_disease_gerd/ article.htm. [accessed on 10 March 2012].

Martin, S. 2006. Care of the professional voice: laryngopharyngeal reflux and singers: "Diabolus in Gula?" The Official Journal of the National Association of Teachers of Singing, 63(2):177-184. November.

McCoy, S. 2004. Your voice, an inside view: multimedia voice science and pedagogy. 2nd edition. Delaware, $\mathrm{OH}$ : Inside View.

Miller, R. 1995. What about the "Pure Vowel" and "vowel modification"? The Official Journal of the National Association of Pedagogues of Singing, 52(1):37-40. September/October.

Miller, R. 2004. Solutions for singers: tools for every performer and teacher. Oxford: Oxford University Press.

Mizyed, I., Fass, S.S., \& Fass, R. 2008. Review article: gastro-oesophageal reflux disease and psychological comorbidity. Alimentary Pharmacology and Therapeutics. 29:351358. November.

Naliboff, B.D., Mayer, M., Fass, R., Fitzgerald, L. Z., Chang, L., Bolus, R. \& Mayer, E.A. 2004. The effect of life stress on symptoms of heartburn. Psychosomatic Medicine, 66(3): 426-34.

Nicholas, J.T. \& Wiklund, I. 2005. Patient reported outcomes in gastroesophageal reflux disease: an overview of available measures. Quality of Life Research, 14(1):21-33. February.

Postma, G.N., Belafsky, P.C. \& Koufman, J.A. 2002. Validity and reliability of the reflux wymptom index (RSI). Journal of Voice, 16(2):274-7. June.

Pregun I., Bakucz, T., Banai, J., Molnár, L., Pavlik, G., Altorjay, I., Orosz, P., Csernay, L., Tulassay, Z. \& Herszényi, L. 2009. Gastroesophageal reflux disease: work-related disease? Digestive Disease, 27(1):38-44. May.

Reid, C.L. 1983. A dictionary of vocal terminology. New York: Joseph Patelson.

Ronkainen, J, Aro, P, Storskrubb, T, Lind, T, Bolling-Sternevald, E, Junghard, O, Talley, NJ, \& Agreus, L. Gastro-oesophageal reflux symptoms and health-related quality of life in the adult general population the Kalixanda study. Alimentary pharmacology \& therapeutics. 2006. April; 23:1725-1733.

Rule, P \& John, V. Your guide to case study research. Pretoria: Van Schaik. 2011.

Ryan, M. 2011. What every singer should know. Fairfor: Echo Library.

Smolander, S. \& Huttunen, K. 2006. Voice problems experienced by Finnish comprehensive school teachers and realization of occupational health care. Logopedics Phoniatrics Vocology, 31:166-177.

Sataloff. $\quad$ R.T. $1991 . \quad$ The professional voice. http://famona.tripod.com/ent/cummings/cumm109.pdf. [accessed on 26 August 2011]. 
Seidl, H., Gundling, F., Schepp, W., Schmidt, T. \& Pehl, C. 2011. Effect of low-proof alcoholic beverages on duodeno gastro-esophageal reflux in health and GERD. Neurogastroenterology and Motility.; 23:145-229. September.

Spiegel, B.M., Roberts, L., Mody, R., Harding, G., Kothari-Talwar, S., Kahrilas, P.J., Camilleri, M.L., Dabbous, O. \& Revicki, D.A. 2010. The development and validation of a nocturnal gastrooesophageal reflux disease symptom severity and impact questionnaire for adults. Alimentary Pharmacology and Therapeutics, 32:591602. June.

Talley, N.J. \& Wiklund, I. 2005. Patient reported outcomes in gastroesophageal reflux disease: an overview of available measures. Quality of Life Research, 14:21-33.

Telford, K., Kralik, D. \& Koch, T. 2005. Acceptance and denial: implications for people adapting to chronic illness: literature review. Journal of Advanced Nursing. October; 55(4):457-464.

Tortora, G.J. \& Anagnostakos, N.P. 1990. Principles of Anatomy and Physiology. New York: Harper and Row.

Tougas, G. \& Banemai, M. 2001. Gastroesophageal reflux disease pathophysiology. Chest Surgery Clinics of North America, 11(3):485-494.

Treuting, P.M., Valasek, M.A. \& Dintzis, S.M. 2012. Upper Gastrointestinal Tract. (In Treuting, P.M. \&, Dintzis, S.M., eds. Comparative anatomy and histology: a mouse ad human atlas. London: Academic Press. pp. 155-176).

Vakil, N. 2007. Review article: the role of surgery in gastro-oesophageal reflux disease. Alimentary Pharmacology and Therapeutics, 25:1356-1372. April.

Ware, C. 1998. Basics of Vocal Pedagogy. New York: McGraw-Hill.

Watson, A.H.D. 2009. The biology of musical performance and performance-related injury. Lanham, MD: Scarecrow Press.

Watson, D.I., Jamieson, G.G., Bessell, J.R. \& Devitt, P.G. 2006. Laparoscopic fundoplication in patients with an aperistaltic esophagus and gastroesophageal reflux. Disease of Esophagus, 19:94-98.

Williams, N. 2011. Why practice nurses need to know about occupational voice loss. Practice Nurse, 41(20):32. September.

Zalewska, A., Miniszewska, J., Chodkiewicz, J. \& Narbutt, J. 2006. Acceptance of chronic illness in psoriasis vulgaris patients. European Academy of Dermatology and Venereology, 21:235-242. February. 